IZA DP No. 7434

Sinners or Saints?

Preachers' Kids and Risky Health Behaviors

Jason J. Delaney

John V. Winters

May 2013 


\title{
Sinners or Saints? Preachers' Kids and Risky Health Behaviors
}

\author{
Jason J. Delaney \\ Georgia Gwinnett College \\ John V. Winters \\ University of Cincinnati \\ and IZA
}
Discussion Paper No. 7434
May 2013

IZA
P.O. Box 7240
53072 Bonn
Germany

Phone: +49-228-3894-0

Fax: +49-228-3894-180

E-mail: iza@iza.org

\begin{abstract}
Any opinions expressed here are those of the author(s) and not those of IZA. Research published in this series may include views on policy, but the institute itself takes no institutional policy positions. The IZA research network is committed to the IZA Guiding Principles of Research Integrity.

The Institute for the Study of Labor (IZA) in Bonn is a local and virtual international research center and a place of communication between science, politics and business. IZA is an independent nonprofit organization supported by Deutsche Post Foundation. The center is associated with the University of Bonn and offers a stimulating research environment through its international network, workshops and conferences, data service, project support, research visits and doctoral program. IZA engages in (i) original and internationally competitive research in all fields of labor economics, (ii) development of policy concepts, and (iii) dissemination of research results and concepts to the interested public.
\end{abstract}

IZA Discussion Papers often represent preliminary work and are circulated to encourage discussion. Citation of such a paper should account for its provisional character. A revised version may be available directly from the author. 
IZA Discussion Paper No. 7434

May 2013

\section{ABSTRACT \\ Sinners or Saints? \\ Preachers' Kids and Risky Health Behaviors}

This paper examines parental influence on adolescent risky behavior, focusing on a unique population: children of the clergy, more commonly known as preachers' kids (PKs). We use latent variable and zero-inflated count models to analyze the effect of being a PK on both uptake and intensity of use of alcohol, cigarettes, marijuana, and other drugs. We find that being a PK significantly reduces alcohol use. This effect comes exclusively from a reduction in the probability of any alcohol use and this increased abstinence among children of the clergy persists into adulthood. These results are consistent with popular conceptions that PKs either take no risks or take large risks. We find no significant effects of being a PK on cigarette uptake or intensity of use but some evidence of a negative PK effect on the uptake of marijuana and other drugs.

JEL Classification: $\quad$ I19, J13, K42, Z12

Keywords: preacher's kid, religion, risky behavior, alcohol, tobacco, substance use

Corresponding author:

John V. Winters

University of Cincinnati

P.O. Box 210371

Cincinnati, OH 45221-0371

USA

E-mail:winterjh@uc.edu 


\section{Introduction}

Adolescents take risks, specifically with sex, with drugs, and with alcohol. They do so out of proportion to both their share of the population and the magnitude of the potential consequences, and the economic impact of these actions is significant. (Irwin et al. 1997; Kandel et al. 1986; Kandel and Logan 1984). Miller et al. (2006) estimated the annual societal cost for underage drinking for the United States in 2001 to be $\$ 61.9$ billion. The economic study of adolescent risk taking is relatively new, and the existing literature focuses primarily on youths as individualistic agents. While traditional economic factors have a significant effect, they explain only a small percentage of the variation in adolescent risk taking (Gruber 2001b). The most developed literature on adolescent risk-taking behavior suggests that social contexts matter, including peer and parental effects on adolescent decision-making (Bronfenbrenner 1979; Ellison and Levin 1998; Fischhoff 1992).

This article examines parental influence on risky behavior by focusing on a particular population: children of the clergy, more commonly known as "preachers' kids" or PKs. Both developmental psychology and social influence theory have suggested that one of the most important influences on adolescent behavior is that of parents (Furby and Beyth-Marom 1992; Irwin et al. 1997; Wilks 1986). This can work in both directions. One on hand, adolescents have a desire to conform to parental expectations, which would generally discourage risky behavior. Alternatively, adolescents also seek to define themselves as distinct from their parents and make their own decisions, which can encourage risky behavior.

PKs are a special group of adolescents who often receive strong pressure from their parents to be model children (Fichter 1992; Norrell 1989). Popular perception and anecdotal evidence have suggested that this leads PKs to be either the best or the worst behaved among 
their peers (Allman 2007). Their parents' choice of profession as moral leaders within their community makes them a good test case for examining parental influence on risky behavior. We used both latent variable and zero-inflated count models to estimate the effect of having a parent in the clergy on the likelihood and intensity of alcohol, cigarette, marijuana, and other drug use.

In the next section, we review the existing literature. The subsequent section discusses a brief model of adolescent risk-taking behavior and potential avenues of parental influence. We then present the data set and our empirical approach. We follow with our results, after which we conclude with a discussion of the results with a view toward the implications for both future research and policy.

\section{Literature}

Several lines of research, within and outside of economics, have addressed adolescent risk-taking behavior (Gruber 2001a). Advances in decision theory, particularly behavioral insights, directly apply to modeling individual adolescent decisions under risk. A vast literature on health and risk-taking behavior, primarily in the study of adult decisions, has provided some empirical insights into both the determinants and consequences of risk-taking behavior (Cawley and Ruhm 2011). The psychological literature on the development of the adolescent mind and on the adolescent decision-making process per se has presented much more complex models than traditional economic models.

Neo-classical decision-making models in economics have made little distinction between adults and adolescents, except insofar as correlations between age and inputs to the utility function imply systematically different decisions (Becker and Murphy 1988). There has been mixed support for fundamental differences between youths and adults (Furby and Beyth-Marom 1992). Existing literature on adolescent decision-making has dispelled the myth that youths 
consider themselves invulnerable. In fact, while both adolescents and adults overestimate risks relative to the objective likelihood, adolescents underestimate longevity, while adult smokers overestimate their longevity (Fischhoff et al. 2000; Reyna and Farley 2006; Viscusi 1990).

Behavioral economists have attempted to incorporate systematic anomalies into their models. O’Donoghue and Rabin (2001) addressed several of these regarding adolescents. Hyperbolic discounting, loss aversion, trend preference, and probability editing may explain some adolescent risk-taking behavior (Frederick et al. 2002). While these models have incorporated some important insights into the determinants of behavior, they have maintained the program of an individualistic analysis of behavior, affected primarily by prices and probabilities.

Increasingly, research has examined the effect of social influences on behavior (Christakis and Fowler 2007; Clark and Lohéac 2007; Fehr and Fischbacher 2002; Fletcher 2010; Lundborg 2006; Manski 2000). While traditional economic factors affect adolescent behavior, unobserved factors seem to dominate (Gruber 2001b). Risk-taking behavior tends to be both social and normative, and often takes place outside of a market environment. Where peer and parental effects have been examined, they have significant influence, even accounting for subjective measurements of harm and traditional economic influences (Barnes et al. 2000; Baumrind 1991; Pacula et al. 2001; Skog 1985). Family structure also has an impact: Argys et al. (2006) and Averett et al. (2011) have suggested that exposure to a special group of peers, namely older siblings, significantly increases adolescent risky behavior.

For our study, parental influence is the most salient factor in the decision to pursue risky activities. Researchers have found that parents significantly affect adolescent risk-taking behavior through both parenting approach and occupation, although the effect of socioeconomic status varies greatly across countries (Baumrind 1991; Richter et al. 2009; Vereecken et al. 2004; 
Wilks 1986). Antecol and Bedard (2007) and Cobb-Clark and Tekin (2011) also have suggested that the presence of a father figure significantly reduces delinquent behavior, especially among young males. Miller (2011) found that maternal work in early adolescence is associated with an increased rate of overweight in the same period, while Hofferth and Pinzon (2011) found that absent fathers' child support does not improve child health. These results are consistent with You and Davis (2011), which found that the amount of time parents, particularly fathers, spend with their children is negatively correlated with the probability of overweight.

Finally, there exists a sizable literature on the influence of religion on health and decision-making. Chiswick and Mirtcheva (2013), for example, find that religious affiliation and religiosity are positively associated with overall health status and psychological health, especially for young adolescents. This is consistent with the broader literature, which generally has found that religious participation reduces risky health behaviors (Lehrer 2004; Mellor and Freeborn 2011; Miller and Hoffmann 1995; Nonnemaker et al. 2003; Rostosky et al. 2004). Religion may serve as an additional mechanism of parental influence, as adolescents are less likely than adults to choose their level of religious participation. Most studies have used one of the three most common measures of religion: religious affiliation, religious service attendance, or subjective religiosity. The evidence has suggested that all three measures have a significant effect on a number of risk-taking behaviors (Amoateng and Bahr 1986; Hadaway et al. 1984; Pacula et al. 2001). In this study, we examined a specific population of parents and adolescents to isolate the effect of parents on their children's risk-taking behavior, controlling for other influences, and found that children of the clergy are significantly less prone to risk-taking behaviors than other adolescent, even those with similar observable levels of religiosity. 


\section{Theory}

Underlying the analysis in this paper is a rational choice model of risky health behavior in which several parameters affect decision making. Adolescents have an endowment, and may, with some objective probability, have an opportunity to play a risky lottery at some cost. This lottery has a subjective probability of a good or bad outcome, each of which has an associated subjective utility. Finally, abstaining from the lottery provides its own outcome with its respective subjective utility.

We model adolescents as agents who maximize subjective expected utility. In each period $t$, there is some probability $\pi_{i t} \in[0,1]$ that individual $i$ will have the chance to play a risky lottery $l$. There are two outcomes of the lottery: $\{G, B\}$. In the good outcome, the agent receives $u_{i}(G \mid)>.u_{i}(B \mid$.$) Denote the subjective probability of receiving the good outcome in$ period $t$ as $q_{i t} \in[0,1]$.

If $i$ does not reach a choice occasion, $i$ receives the utility of the outside option, denoted $a$ (for abstinence): $u_{i}\left(a_{t} \mid\right.$.). If $i$ reaches a choice occasion, then $i$ seeks to maximize utility by choosing the lottery or choosing to abstain:

$$
\max _{x \in\{a, l\}} u_{i}=u_{i}\left(x_{t}, c_{t} \mid \theta_{i t}\right)=\max \left\{u_{i}\left(a_{t}, c_{t} \mid \theta_{i t}\right) ; u_{i}\left(l_{t}, c_{t} \mid \theta_{i t}\right)\right\}
$$

where $c_{t}$ represents consumption of all other goods, and $\theta_{i t}$ is a vector of idiosyncratic characteristics of individual $i$ at time $t$. If $i$ chooses $l$, she pays $p_{l}$ and participates in the lottery. Under expected utility maximization, this becomes:

$$
\max \left\{u_{i}\left(a_{t}, c_{t} \mid \theta_{i t}\right) ; q_{i t} u_{i}\left(G, c_{t} \mid \theta_{i t}\right)+\left(1-q_{i t}\right) u_{i}\left(B, c_{t} \mid \theta_{i t}\right)\right\}
$$

Assume each person receives an idiosyncratic endowment every period, $e_{i t}$. The constraint is then:

$$
c_{t}+p_{l}(l=1) \leq e_{i t}
$$


Under this constraint, we can describe the adolescent decision as the solution to the constrained optimization problem:

$$
\begin{aligned}
\max _{\mathrm{x}_{\mathrm{t}, \mathrm{y}_{\mathrm{t}}}}\left(1-\pi_{i t}\right) & u_{i}\left(a_{t}, c_{t}\right) \\
& +\pi_{i t}\left(I\left(x_{t}=a\right)\left(u_{i}\left(a_{t}, c_{t}\right)\right)+I\left(x_{t}=l\right)\left(q_{i t} u_{i}\left(G, c_{t}\right)+\left(1-q_{i t}\right) u_{i}\left(B, c_{t}\right)\right)\right)
\end{aligned}
$$

subject to $c_{t}+p_{l}\left(x_{t}=l\right) \leq e_{i t}$

In this model, parents have several effects on adolescent decision-making. Parental influence can enter through the endowment $\left(e_{i t}\right)$, by affecting the likelihood of encountering a choice occasion $\left(\pi_{i t}\right)$, by affecting their children's subjective probability of receiving a good outcome from making a risky decision $\left(q_{i t}\right)$ or by directly affecting preferences $\left(u_{i}\right)$.

Data availability is a serious constraint in implementing the model, particularly with respect to parental influence. We cannot identify the mechanism of parental influence, but we can discern the overall effect by isolating other influences and examining the effect of parental occupation in a reduced form equation. We have measures of the intensity of use within a particular time: $y_{i T}=\sum_{t \in T} I\left(x_{t}=l\right)$ as well as whether adolescents have engaged in a particular risky activity whatsoever, $z_{i T}=\left\{\begin{array}{l}0 \text { if } y_{i T}=0 \\ 1 \text { if } y_{i T}>0\end{array}\right.$.

We hypothesize that PKs will have lower average intensity of use of alcohol, cigarettes, marijuana and other drugs. The dual stereotype of PKs represents a joint hypothesis that the probability of use is lower, but conditional on use, the intensity of use is higher. In our theoretical model, this corresponds to a decrease in the average value of $\pi_{i t}$ for PKs, but an increase in the number of occasions in which the lottery is chosen, conditional on reaching a choice occasion. One set of potential mechanisms for this dual effect would include the availability of substitute activities, reducing the probability of a choice occasion, combined with 
a higher marginal utility of the risky activity. In the next section we discuss the available data and our empirical strategy for assessing the impact of having a parent in the clergy.

\section{Data and Empirical Approach}

The analysis in this paper required detailed data on parental occupation and participation in risky activities by young people. This paper used data from the National Longitudinal Survey of Youth 1979 Cohort (NLSY79). ${ }^{1}$ The initial NLSY79 survey was administered in 1979 to a sample of 12,686 male and female youths who were 14-22 years old. Follow-up surveys were administered annually until 1994 and every two years since 1994. Many respondents drop from the sample over time, and by 2008 the sample included only 7757 individuals. We classified individuals as preachers' kids by constructing an indicator variable, defining a youth as a PK if his or her father's three-digit primary occupation code was "086 - Clergymen"; no mothers in the sample had this occupation code. ${ }^{2}$

This study investigated four risky health behaviors at various points in the lives of the respondents: alcohol consumption, cigarette smoking, marijuana use and other drug use. The NLSY79 asked questions about these during various years of the survey. Because the survey was administered to the same individuals repeatedly, we had two options: we could either treat the data as a panel or as a series of cross-sections. Because our primary treatment variable was fixed within individuals over time, many panel estimation techniques offer little benefit. We opted for a series of cross-sections, which allows the effect of the treatment variable to vary over time.

\footnotetext{
${ }^{1}$ We also considered several other datasets including the National Longitudinal Survey of Adolescent Health (AddHealth), the National Longitudinal Survey of Youth 1997 Cohort (NLSY97), and the National Survey on Drug Use and Health (NSDUH). However, these other datasets do not provide detailed information on parental occupation needed to identify whether a young person is a preacher's kid. NLSY79 contains data on both detailed parental occupation and risky behaviors.

${ }^{2}$ Note that parents choose their own occupations in a non-random manner and our estimates below should be interpreted as descriptive and not necessarily causal. A second occupation code, "090 - Religious workers, n.e.c." was also considered, but the exact job functions (e.g., music director, youth coordinator, church secretary, etc.) for such individuals were unclear, so the analysis here only uses occupation code "086" to define PKs. Including the second group as PKs does not significantly alter the results.
} 
We examined three alcohol-related outcomes: 1) whether the respondent drank any alcohol during the month immediately preceding the survey, 2) the number of days that the respondent drank alcohol in the previous month, and 3) the number of days in the previous month that the respondent drank five or more alcoholic drinks at one time. Alcohol-related survey questions were asked in 1982, 1983, 1984, 1985, 1988, 1989, 1992, 1994, 2002, 2006, and 2008. During the early years, some respondents were of legal drinking age while others were not. $^{3}$

We examined three outcomes related to cigarette smoking: 1) whether the respondent had smoked 100 or more cigarettes during their lifetime, 2) whether the respondent smoked any cigarettes in the previous month, and 3) the number of cigarettes the respondent smoked in the previous month. These cigarette smoking variables were only available for 1984, 1992, 1994, 1998, and 2008. All respondents were of legal smoking age by 1984. For marijuana and other drug use, we examined only two variables from the 1980 survey: whether the respondent used any marijuana in the previous year and whether the respondent used any other drugs in the previous year. $^{4}$

Summary statistics for the risky health behaviors we examined are reported in Table 1 separately for PKs and non-PKs. Comparing means for the two groups, PKs engaged in fewer risky behaviors on average during the early years of the survey, but the differences narrowed and even reversed in later years. This supports our decision to estimate separate regressions for each year instead of pooling the data across years. However, simple differences in means may be

\footnotetext{
${ }^{3}$ We considered including the legal status of alcohol consumption by age as one of our explanatory variables, but this was not possible as the public use files do not include data on the state of residence for survey respondents and the minimum drinking age varied greatly across states and years during this time. All of our respondents were at least 14 in 1979 and so the youngest respondent would have turned 21 in 1986. Our results do not appear to show a difference in behavior before and after this year, suggesting that controlling for age and region may be capturing any effect of minimum drinking age on alcohol consumption behavior.

${ }^{4}$ The count data we examine for alcohol and cigarettes are not available for marijuana and other drug use.
} 
misleading, so it is important to account for differences in individual characteristics and use more appropriate statistical methods.

The dataset contains a large number of individual characteristics that we included as control variables. These included dummy variables for year of age, whether an individual is female, Black, Hispanic, lived in an SMSA in 1979, region of residence in 1979, father's education, mother's education, whether the mother worked, whether the respondent lived with a biological father or other father figure at age 14, the presence and number of siblings, the presence and number of older siblings, and the Duncan Socioeconomic Index (SEI) of occupational prestige for the father's occupation. We also examined if and how the PK effects change with controls for religious affiliation and the frequency of religious attendance in $1979 .^{5}$ Doing so allowed us to separately compare PKs to both an "average youth" and an average youth with similar religious characteristics to a PK.

We estimated both latent variable and zero-inflated count models. Latent variable models were estimated using logistic regression for binary dependent variables. ${ }^{6}$ More specifically, we modeled a latent variable, $y^{*}$, as a linear function of PK status and the other individual characteristics, $X$, included as control variables:

$y^{*}=\alpha(P K)+X \beta+\varepsilon$

Our interest is in $\alpha$, the effect of being a PK on the latent outcome $y^{*}$. Our first hypothesis is that being a PK reduces $y^{*}$. We cannot directly observe $y^{*}$ but instead observe a binary dependent variable $y$, which is a function of $y^{*}$ :

\footnotetext{
${ }^{5}$ All explanatory variables are as reported in the 1979 survey and do not vary over time. We also experimented with examining differences by child's education status. Unfortunately, because we initially observe respondents during ages 14-22, the final education level is not yet determined for most of the respondents during the early years of the survey and observed education is highly collinear with age. We did however, examine differences by education for several later survey years and our analysis suggests that the PK effect does not significantly vary by education level during adulthood.

${ }^{6}$ See Wooldridge (2002) for additional details.
} 
$y=\left\{\begin{array}{l}0 \text { if } y^{*} \leq 0 \\ 1 \text { if } y^{*}>0\end{array}\right.$

In other words, $y$ takes on a value of one if the latent variable exceeds a threshold and zero if it does not. The logit model assumes that the error term, $\varepsilon$, has a logistic distribution. ${ }^{7}$

Some of the dependent variables are counts, i.e., non-negative integer values, with excess zeros. $^{8}$ In these cases, we modeled the data-generating process using a zero-inflated negative binomial (ZINB) model. ${ }^{9}$ Our theoretical model suggests that the source of the excess zeros is likely to be a separate data-generating process, in which the probability of encountering a choice occasion $\left(\pi_{i t}\right)$ played the primary role. An intuitive interpretation here is some selection mechanism: based on observable characteristics, some individuals were likely to have a value of $\pi_{i t}$ close to zero for all periods. Using a mixture model allows us to separately identify determinants of the probability of uptake of risky health behaviors as well as the determinants of the intensity of use.

Formally, this model assumes that the distribution of counts is given by:

$$
g(y)=\left\{\begin{array}{cc}
f_{1}(0)+\left(1-f_{1}(0)\right) f_{2}(0) & \text { if } y=0 \\
\left(1-f_{1}(0)\right) f_{2}(y) & \text { if } y \geq 1
\end{array}\right.
$$

We chose the logit model for $f_{1}(\cdot)$ and the negative binomial density for $f_{2}(\cdot)$. This specification allows for two different processes to generate observed zeros: they are generated either by the logit process, which corresponds to the "choice encounter" portion of our theoretical model, or by the negative binomial process, which corresponds to constrained utility maximization conditional on facing a choice.

\footnotetext{
${ }^{7}$ The binary model results are also qualitatively robust to probit and linear probability model specifications.

${ }^{8}$ For days drank in the last month, about a third of the responses were zeros. For days with five of more drinks, about two-thirds of responses were zeros. For number of cigarettes in the last month, about $70 \%$ of responses were zeros.

${ }^{9}$ For a brief overview of modified count models, see Cameron and Trivedi (2005 pp.665-91).
} 
Previous evidence suggested that cigarette smoking data can be modeled effectively using a ZINB model. Sheu et al. (2004) examined the effect of a price increase on smoking behavior and were able to separate out the effect on smoking prevalence and smoking consumption. The model allowed the authors to conclude that the decrease in smoking from the price increase was primarily a consumption effect rather than a prevalence effect. Our hypothesis is that the PK effect, if any, primarily resulted in a decrease in uptake of risky behavior (a prevalence effect) with a smaller offsetting increase in consumption, conditional on uptake. ${ }^{10}$

\section{Results}

This section presents the results of the empirical analysis examining the effects of being a preacher's kid on the decision to engage in a number of risky health behaviors. Table 2 presents the effects on alcohol consumption, Table 3 presents results for cigarette smoking, and Table 4 presents results for marijuana and other drug use. All results include the basic set of controls, but we present results both without and with additional controls for religious affiliation and attendance in 1979 in panels A and B of the tables. Being a PK had a considerable effect on a respondent's religious attendance and affiliation, so these partially served as mechanisms through which the effect of being a PK operated. The panel A results (without the additional religious controls) compare PKs to the average respondent, while the panel B results compare PKs to respondents with similar religious affiliation and attendance frequency.

\section{Alcohol Consumption}

\footnotetext{
${ }^{10}$ In addition to theoretical considerations, empirical tests confirmed that the ZINB model is the appropriate one for the count data we examine. We also considered using Poisson regression, negative binomial regression, and zeroinflated Poisson (ZIP) regression models, but the count variables we examined are overdispersed and contain excess zeros. The significance of the overdispersion coefficient, $\alpha$, the measures of model fit, as well as results from Vuong tests for excess zeros indicated that ZINB was indeed the preferred model for the count variables we investigated. However, using a ZIP model produced qualitatively similar results
} 
Our results support the notion that preachers' kids are less likely than their peers to consume alcohol. This effect comes from an increase in the likelihood of abstinence from alcohol. Conditional on consuming alcohol, on the other hand, preachers' kids certainly do not consume less than their peers, and our results weakly suggest that they consume more than similar adolescents.

The first column of Table 2 reports the odds ratio, estimated via logit, associated with being a PK. ${ }^{11}$ The dependent variable is binary—whether the respondent consumed any alcohol in the past month for several different years. An odds ratio greater than one suggests that PKs are more likely than non-PKs to have drunk any alcohol, and an odds ratio less than one suggests that PKs are less likely to have drunk alcohol. The odds ratios in Panel A were less than one for every year considered and statistically significant for most years. This suggests that being a PK reduced the probability of consuming any alcohol. The odds ratio of 0.344 in 1982 suggests that the odds of a PK consuming any alcohol in the past month were $34.4 \%$ of those of an otherwise similar adolescent. Given that roughly $65 \%$ of all respondents had drunk some alcohol in the previous month for 1982, the estimated effect of being a PK was large and meaningful. The odds ratio decreased to its minimum in 1985 at 0.219 , after which it generally increased over time. After 1989 the estimate was statistically significant in only one year, 2002. The effect of being a PK, therefore, attenuated over time as individuals aged and developed their own values and beliefs. $^{12}$

\footnotetext{
${ }^{11}$ Odds ratios measure the probability that $y=1$ relative to the probability that $y=0$. Logit coefficients report the partial effects of regressors on log-odds ratios. Log-odds ratios are transformed to odds ratios by the exponential function.

${ }^{12}$ In results not shown we also examined a smaller sample of individuals that remain in the survey from 1979 to 2008 to examine whether the attenuation of the PK coefficient was due to attrition from the sample. We found that the PK effects for the reduced sample were very similar to those for the full sample, suggesting that sample attrition was not causing the decrease in the PK effect over time.
} 
Including controls for religious attendance and affiliation in Panel B of the first column of Table 2 decreased the strength of the estimated effects of being a PK on any alcohol consumption. This is consistent with the notion that parental influence on adolescent behavior is partly mediated by religion. Even controlling for religious attendance and affiliation, however, being a PK still had a large and significantly negative effect on alcohol consumption between 1982 and 1988. The odds ratio in 1982 indicates that the odds of a PK having consumed any alcohol in the past month were $52.4 \%$ of those of respondents with similar religious attendance and affiliation. As in Panel A, the odds ratio decreased through 1985 and then increased over time.

The second and third columns of Table 2 report the effect of being a PK on the number of days the respondent drank alcohol in the month before the survey. This variable was unavailable for 1982 and 1992, so table cells are left blank for those years. Our mixture model allowed us to break the effect into two components: the effect of being a PK on having a "Certain Zero", and the effect of being a PK on the number of days drank, conditional on not having a certain zero. The "Certain Zero" column presents the odds ratio for PKs having had no drinks at all in the past month. In this case an odds ratio greater than one indicates lower alcohol use because we are predicting the odds of abstinence instead of consumption. ${ }^{13}$ As with the previous results, the certain zero effect was significant for years 1983-1989 and 2002. The odds ratio for 1983 indicates that the odds of a PK certainly having had no drinks were 6.18 times those of a similar respondent, suggesting that PKs were considerably more likely to abstain from alcohol.

\footnotetext{
${ }^{13}$ The "Certain Zero" equation is conceptually similar to the logit results for any alcohol consumption discussed previously but there are two subtle differences. First, our earlier results estimate the odds of alcohol consumption, while the certain zero equations reflect the odds of abstaining from alcohol, which are multiplicative inverses. Second, the ZINB model separates zero consumption into two groups generated from distinct processes: certain zeros and zeros due to the process generating the counts.
} 
The count equation results in Table 2 are reported as incidence ratios, so that a ratio greater than one indicates that being a PK increased the frequency of alcohol use and a ratio less than one indicates a negative PK effect on the frequency of alcohol use. The count equation results in the third column were not statistically significantly different from one. The incidence ratio estimates were greater than one for seven of the nine years considered, weakly suggesting that conditional on not being a certain zero, PKs drink more frequently than their counterparts. However, because few of the PKs drink at all, we were unable to make strong inferences about the PK effect on frequency conditional on drinking. The PK effect comes primarily from an increased likelihood of abstinence.

Controlling for religious affiliation and attendance in Panel B had two effects on the ZINB estimates. The magnitude and significance of the certain zero odds ratios decreased, indicating that religious affiliation and attendance accounted for some of the PK effect. The magnitudes for the incidence ratios in the "Count" column increased, but were again never statistically significant at conventional levels.

Figure 1 summarizes the data and illustrates these effects over the course of a PK's life. Assuming we have an average PK who was 18 years of age at the time of the survey, the first panel in Figure 1 shows estimated odds ratios for being in the Certain Zero group at various ages. The increase in the likelihood of abstinence among PKs is indicated by the height of the curve in the first panel, and the attenuation over time is visible as the odds ratio eventually reaches one. The second panel presents incidence ratios of number of drinks conditional on not being a Certain Zero, estimated across a number of years. The incidence ratio of one never falls outside the $95 \%$ confidence interval, but the point estimate is greater than one until the mid-40s. 
The final two columns of Table 2 report the PK effect on the number of days the respondent drank five or more alcoholic beverages in the previous month estimated via ZINB regression. Drinking five or more drinks at one time constitutes binge drinking and can lead to considerable negative health effects. Unfortunately, this variable was only available for three years, 1983-1985. The "Certain Zero" results in Panel A are consistent with earlier results: being a PK significantly increased the odds of abstaining from binge drinking in all three years and the odds ratios are quite large. The odds ratio of 7.072 in 1984 suggests that a PK was more than seven times more likely than a similar non-PK to abstain with certainty from binge drinking. The count equation in the last column of Panel A reports incidence ratios for binge drinking conditional on not being a certain zero. Though not precisely estimated, the incidence ratios for 1983 and 1984 suggest that conditional on not being a certain zero, PKs within our sample engaged in binge drinking twice as frequently as their counterparts.

Including the additional religious controls in Panel B again had two effects. First, it reduced the magnitudes of the odds ratios for Certain Zero and the effect for 1985 was no longer significant. Second, it increased the incidence ratios for the count equation in 1983 and 1984 to 2.537 and 3.271, respectively, and the effect in 1984 became statistically significant with a pvalue of 0.052 . The estimates remained somewhat noisy and the incidence ratio in 1985 was very close to unity, but there is some evidence that, conditional on drinking, PKs engaged in binge drinking more frequently than non-PKs.

Our results are consistent with our first hypothesis: PKs drink less than their peers. This reduction is the result of a strong and significant decrease in the uptake of alcohol use, rather than any reduction in intensity of use. Within our sample, those PKs who did not abstain drank more frequently than their peers, but our estimates are sufficiently imprecise that we cannot draw 
a conclusion about the broader population. Certainly we cannot conclude that PKs, conditional on some alcohol use, consumed alcohol with less intensity than their peers.

\section{Cigarette Smoking}

Unlike alcohol use, our analysis of cigarette smoking behavior indicates no significant effect on preachers' kids whatsoever. The NLSY survey asked respondents about cigarette smoking for many fewer years than for alcohol consumption. The first column of Table 3 presents odds ratios from a logistic regression of having smoked at least 100 cigarettes in one's lifetime, with higher values indicating higher odds for PKs. For Panel A, the effects were small and positive, and none were statistically significant. Controlling for observable religion measures increased the odds ratios, but they remained statistically insignificant at conventional levels, though the 1994 estimate was close with a p-value of 0.129 and an odds ratio of 2.059 .

The second column reports logit results of the PK effect on whether the respondent smoked any cigarettes in the past month. The odds ratio in 1984 for Panel A was 0.487 and was marginally insignificant with a p-value equal to 0.104 , which could weakly suggest that being a PK reduced the odds of smoking. In subsequent years, however, the odds ratio in Panel A increased to greater than one but is not statistically significant. Adding the additional religious controls in Panel B, however, increased the odds ratio for every year. For 2008, the odds ratio was 2.442 with a p-value of 0.120 , which may weakly suggest that being a PK increased the odds of smoking later in life.

The third and fourth columns present results from a zero-inflated negative binomial regression model for the number of cigarettes smoked per day in the previous month. Both without and with the additional religious controls, the effects for both the certain zero and count equations were fairly moderate and not statistically significant at conventional levels. Therefore, 
we were unable to make strong inferences about the effects of being a PK on the decision to smoke cigarettes.

The difference between the strong and significant effect of being a PK on alcohol use and the lack of an effect on cigarette use is noteworthy. Given the social mores at the time of data collection, it may be the case that cigarette use was subject to less social disapproval than alcohol use among PKs, despite the health risks attendant to cigarette use. We consider this further in the conclusion.

\section{Marijuana and Other Drugs}

The effect of being a preacher's kid on use of marijuana and other drugs is more consistent with the effect on alcohol use than the effect on cigarette use. The NLSY contained less detailed information on marijuana and other drug use than alcohol, but the 1980 survey provided two questions useful for our analysis: whether the respondent used any marijuana in the previous year and whether the respondent used any other drugs in the previous year.

We estimated the effect of being a PK on each of these variables using logistic regression with results reported in Table 4. Being a PK significantly reduced the odds of both marijuana and other drug use in 1980. Within our sample, the odds of a PK using marijuana were $46.8 \%$ those of a comparable non-PK and the odds of a PK using other drugs were $22.6 \%$ of those of a nonPK. Including the additional religious controls, however, increased the odds ratios and the PK effect was no longer statistically significant at conventional levels. The estimated magnitudes were in both cases roughly similar to the effects on alcohol use, although the decreased variability in use reduced the precision of the estimates. 


\section{Conclusion}

This study investigated the interactive effects of religious and parental influences on adolescent decision-making about risky health behaviors by looking at the specific subpopulation of children of the clergy. Preachers' kids are an interesting group in that they suffer from opposing stereotypes: that they are either the best behaved or the worst behaved of their peers (Allman 2007). In addition, their parents and families — and by extension, PKs themselves - hold a special place in society as public moral actors, allowing us to examine the effect of parents on their children's behavior. The ability to not only observe this effect, but also to differentiate between the effect on uptake and the effect on intensity of use allows us to identify specific recommendations for reducing risky adolescent behavior.

We used both latent-variable models and zero-inflated count models to examine both the uptake and intensity of risky behavior among preachers' kids. Latent-variable models allowed us to model the determinants of engaging in risky behavior, allowing us to test our first research hypothesis: that PKs were less likely to engage in risky behavior. The zero-inflated count models allowed us to model the decision-making process in two parts. Our sample includes some individuals who never faced decisions involving risk, as well as those who, when confronted with a decision involving risk, chose a particular level of engagement in risky behavior. The mixture model allowed us to test the hypothesis that this reduction in risky behavior comes primarily from a decrease in uptake, rather than decreased intensity of use: PKs are less likely to engage in risky behavior, but, conditional on having chosen to do so, they are likely to engage in it with greater intensity. We considered four types of risky decisions: alcohol use, cigarette use, marijuana use, and other drug use. 
Our results suggest that our first hypothesis appears to hold: preachers' kids were on average less likely than comparable adolescents to drink alcohol. This effect was not only statistically significant but also economically significant. Parents in the clergy appear to have influenced their children's risky behaviors through a significant reduction in uptake of alcohol use. In their late teens and early twenties, the odds of an otherwise similar adolescent consuming any alcohol in the past month were 3-4 times those of a preacher's kid.

Using the mixture model to decompose this effect into uptake and intensity effects strengthens the evidence for decreased uptake of alcohol. The odds of preachers' kids in their late teens and early twenties abstaining from alcohol were 4 to 9 times more than those of their peers. Including other controls indicated that some of the effect is mediated by religious attachment, but the odds of abstention from alcohol for PKs remain 2 to 6 times greater than peers with similar levels of religious attachment.

The second part of the joint hypothesis is consistent with our results, but lack of power in our tests prevents us from drawing strong conclusions about intensity of use in the broader population of PKs. Removing those PKs who would be moderate drinkers from the pool of drinkers generally increased the observed conditional mean of PKs who do drink, though the estimates are imprecise. These effects, taken together, are consistent with the "saints or sinners" set of stereotypes that are broadly held regarding the behavior of PKs.

We also found that the odds of PKs using marijuana and other illicit drugs were onequarter to one-half those of their peers, but these results were not statistically significant when we included controls for religious affiliation and attendance, indicating that religious attachment may have been the driving force behind abstinence in these cases. The data availability prevents 
the use of count models to conduct an analysis analogous to that of alcohol use, but the latentvariable results are similar in magnitude to those of alcohol use.

In our examination of cigarette smoking, we found no significant PK effect on cigarette smoking, perhaps suggesting that parents in the clergy were less condemning of cigarettes than alcohol, marijuana and other drugs, despite the serious health risks presented by cigarettes. This raises questions about the interaction between social acceptability and the uptake of risky, but socially sanctioned, health behaviors, such as detrimental eating habits or contact sports. If parents primarily affect their children's decisions through the uptake of risky behaviors, parents could exacerbate risky behavior by facilitating opportunities to engage in these activities. Additional research on the ways parents affect adolescent engagement in such activities could help to differentiate between parental contributions to health and to normative social behavior.

The negative PK effects on risky behaviors attenuated over time as the influence of parents faded. The PK effects were also attenuated by controlling for religious affiliation and attendance suggesting that these are important mechanisms through which the PK effect operates.

These results support previous literature suggesting that both adolescent religious participation and parental influence affect adolescent risky behaviors in important ways. The preachers' kids in our sample engaged in risky health behaviors less frequently than their peers, but with no less intensity. Our use of an innovative modeling technique allowed us to observe that the reduction in risky behavior is driven primarily by a decrease in uptake, rather than a decrease in intensity. Future research may benefit from similar use of theoretically-motivated mixture models to differentiate between various processes that drive decision making. Both 
contact sports and risky sexual behavior seem like potentially fruitful areas for the application of similar modeling techniques to analyze adolescent behavior.

Taken together, our results are consistent with the notion that parents can have an effect on their children's risky decisions through an effect on the set of available options. It seems likely that preachers' kids would tend to be more involved in church activities and have friends who share their parents' values. Both policy-makers and parents should be aware that if social activities are substitutes, then our evidence suggests that an increase in the availability of social activities that do not feature the opportunity for risky decisions is an effective way to reduce uptake of risky behaviors. Given the economic consequences of adolescent risk-taking, alternative social activities may be efficiency-enhancing. 


\section{References}

Allman, Tara J. 2007. An analysis of the stereotypes of preacher's kids and its application on their spouses. Theses, Dissertations and Capstones. Paper 13. Retrieved from: http://mds.marshall.edu/etd/13

Amoateng, A.Y., \& Bahr, S.J. (1986). Religion, family, and adolescent drug use. Sociological Perspectives, 29(1), 53-76. Retrieved from: http://www.jstor.org/stable/1388942

Antecol, H., \& Bedard, K. (2007). Does single parenthood increase the probability of teenage promiscuity, substance use, and crime? Journal of Population Economics, 20(1), 55-71. doi: 10.1007/s00148-005-0019-X

Argys, L.M., Rees, D.I., Averett, S.L., \& Witoonchart, B. (2006). Birth order and risky adolescent behavior. Economic Inquiry, 44(2), 215-233. doi: 10.1093/ei/cbj011

Averett, S., Argys, L., \& Rees, D. (2011). Older siblings and adolescent risky behavior: Does parenting play a role? Journal of Population Economics, 24(3), 957-978. doi: $10.1007 / \mathrm{s} 00148-009-0276-1$

Barnes, G.M., Reifman, A.S., Farrell, M.P., \& Dintcheff, B.A. (2000). The effects of parenting on the development of adolescent alcohol misuse: A six-wave latent growth model. Journal of Marriage and Family, 62(1), 175-186. doi: 10.1111/j.1741-3737.2000.00175.x

Baumrind, D. (1991). The influence of parenting style on adolescent competence and substance use. The Journal of Early Adolescence, 11(1), 56-95. doi: 10.1177/0272431691111004

Becker, G.S., \& Murphy, K.M. (1988). A theory of rational addiction. Journal of Political Economy, 96(4), 675-700. Retrieved from: http://www.jstor.org/stable/1830469

Bronfenbrenner, U. (1979). The ecology of human development: Experiments by nature and design. Cambridge, Mass.: Harvard University Press. 
Cameron, A.C., \& Trivedi, P.K. (2005). Microeconometrics methods and applications. New York: Cambridge University Press.

Cawley, J., \& Ruhm, C.J. (2011). The economics of risky health behaviors (IZA Discussion Paper No. 5728). Bonn: Forschunginstitut zur Zukunft der Arbeit. Retrieved from http://ftp.iza.org/dp5728.pdf.

Chiswick, B. R., \& Mirtcheva, D. M. (2013). Religion and child health: Religious affiliation, importance, and attendance and health status among American youth. Journal of Family and Economic Issues, 34(1), 120-140. doi:10.1007/s10834-012-9312-5

Christakis, N.A., \& Fowler, J.H. (2007). The spread of obesity in a large social network over 32 years. New England Journal of Medicine, 357(4), 370-379. doi: 10.1056/NEJMsa066082

Clark, A.E., \& Lohéac, Y. (2007). "It wasn't me, it was them!" Social influence in risky behavior by adolescents. Journal of Health Economics, 26(4), 763-784. doi: 10.1016/j.jhealeco.2006.11.005

Cobb-Clark, D.A., \& Tekin, E. (2011). Fathers and youth's delinquent behavior (National Bureau of Economic Research Working Paper Series, No. 17507) Retrieved from: http://www.nber.org/papers/w17507.

Ellison, C.G., \& Levin, J.S. (1998). The religion-health connection: Evidence, theory, and future directions. Health Education \& Behavior, 25(6), 700-720. doi: $10.1177 / 109019819802500603$

Fehr, E., \& Fischbacher, U. (2002). Why social preferences matter - the impact of non-selfish motives on competition, cooperation and incentives. The Economic Journal, 112(478), C1-C33. doi: 10.1111/1468-0297.00027

Fichter, J.H. (1992). Wives of Catholic clergy. Sheed \& Ward, New York. 
Fischhoff, B. (1992). Risk taking: A developmental perspective. In J.F. Yates (Ed.). Risk-taking behavior (pp. 133-162). Wiley series in human performance and cognition. Oxford: John Wiley \& Sons.

Fischhoff, B., Parker, A.M., Bruin, W.B.d., Downs, J., Palmgren, C., Dawes, R., \& Manski, C.F. (2000). Teen expectations for significant life events. The Public Opinion Quarterly, 64(2), 189-205. Retrieved from: http://www.jstor.org/stable/3078815

Fletcher, J.M. (2010). Social interactions and smoking: evidence using multiple student cohorts, instrumental variables, and school fixed effects. Health Economics, 19(4), 466-484. 10.1002/hec. 1488

Frederick, S., Loewenstein, G., \& O'Donoghue, T. (2002). Time discounting and time preference: A critical review. Journal of Economic Literature, 40(2), 351-401. doi: $10.1257 / 002205102320161311$

Furby, L., \& Beyth-Marom, R. (1992). Risk taking in adolescence: A decision-making perspective. Developmental Review, 12(1), 1-44. doi: 10.1016/0273-2297(92)90002-J

Gruber, J. (Ed.). (2001). Risky behavior among youths: An economic analysis. Chicago: University of Chicago Press.

Gruber, J. (2001). Youth smoking in the 1990's: Why did it rise and what are the long-run implications? The American Economic Review, 91(2), 85-90. doi: 10.1257/aer.91.2.85

Hadaway, C.K., Elifson, K.W., \& Petersen, D.M. (1984). Religious involvement and drug use among urban adolescents. Journal for the Scientific Study of Religion, 23(2), 109-128. Retrieved from: http://www.jstor.org/stable/1386103 
Hofferth, S. L., \& Pinzon, A. M. (2011). Do nonresidential fathers' financial support and contact improve children's health? Journal of Family and Economic Issues, 32(2), 280-295. doi:10.1007/s10834-010-9237-9

Irwin, C.E., Igra, V., Eyre, S., \& Millstein, S. (1997). Risk-taking behavior in adolescents: The paradigm. Annals of the New York Academy of Sciences, 817(1), 1-35. doi: 10.1111/j.1749-6632.1997.tb48193.x

Kandel, D.B., Davies, M., Karus, D., \& Yamaguchi, K. (1986). The consequences in young adulthood of adolescent drug involvement. An overview. Archives of General Psychiatry, 43(8), 746-754. doi: 10.1001/archpsyc.1986.01800080032005

Kandel, D.B., \& Logan, J.A. (1984). Patterns of drug use from adolescence to young adulthood: I. Periods of risk for initiation, continued use, and discontinuation. American Journal of Public Health, 74(7), 660-666. doi: 10.2105/AJPH.74.7.660

Lehrer, E.L. (2004). Religion as a determinant of economic and demographic behavior in the United States. Population and Development Review, 30(4), 707-726. doi: 10.1111/j.17284457.2004.00038.x

Lundborg, P. (2006). Having the wrong friends? Peer effects in adolescent substance use. Journal of Health Economics, 25(2), 214-233. doi: 10.1016/j.jhealeco.2005.02.001

Manski, C. (2000). Economic analysis of social interactions. The Journal of Economic Perspectives, 14(3), 115-136. doi: 10.1257/jep.14.3.115

Mellor, J.M., \& Freeborn, B.A. (2011). Religious participation and risky health behaviors among adolescents. Health Economics, 20(10), 1226-1240. doi: 10.1002/hec.1666 
Miller, A.S., \& Hoffmann, J.P. (1995). Risk and religion: An explanation of gender differences in religiosity. Journal for the Scientific Study of Religion, 34(1), 63-75. doi: $10.2307 / 1386523$

Miller, D.P. (2011). Maternal work and child overweight and obesity: The importance of timing. Journal of Family and Economic Issues, 32(2), 204-218. doi:10.1007/s10834010-9244-x

Miller, T.R., Levy, D.T., Spicer, R.S., \& Taylor, D.M. (2006). Societal costs of underage drinking. Journal of Studies on Alcohol and Drugs, 67, 519-528. Retrieved from: http://www.ncbi.nlm.nih.gov/pubmed/16736071

Nonnemaker, J.M., McNeely, C.A., \& Blum, R.W. (2003). Public and private domains of religiosity and adolescent health risk behaviors: evidence from the National Longitudinal Study of Adolescent Health. Social Science \& Medicine, 57(11), 2049-2054. doi: $10.1016 / \mathrm{S} 0277-9536(03) 00096-0$

Norrell, J.E. (1989). Clergy family satisfaction. Family Science Review, 2(4), 337-346. Retrieved from: http://familyscienceassociation.org/archived\%20journal\%20articles/volume2/FSR-Volume\%202\%20Number\%204/Vol\%202\%20No\%204\%20Article\%205.PDF

O'Donoghue, T., \& Rabin, M. (2001). Risky behavior among youths: Some issues from behavioral economics. In J. Gruber (Ed.). Risky behavior among youths: An economic analysis. Chicago: University of Chicago Press. Retrieved from: http://www.nber.org/chapters/c10686.pdf

Pacula, R.L., Grossman, M., Chaloupka, F.J., O'Malley, P.M., Johnston, L.D., \& Farrelly, M.C. (2001). Marijuana and youth. In J. Gruber (Ed.). Risky behavior among youths: An 
economic analysis. Chicago: University of Chicago Press. Retrieved from: http://www.nber.org/chapters/c10691.pdf

Reyna, V.F., \& Farley, F. (2006). Risk and rationality in adolescent decision making. Psychological Science in the Public Interest, 7(1), 1-44. doi: 10.1111/j.15291006.2006.00026.x

Richter, M., Vereecken, C., Boyce, W., Maes, L., Gabhainn, S., \& Currie, C. (2009). Parental occupation, family affluence and adolescent health behaviour in 28 countries. International Journal of Public Health, 54(4), 203-212. doi: 10.1007/s00038-009-8018-4

Rostosky, S.S., Wilcox, B.L., Wright, M.L.C., \& Randall, B.A. (2004). The impact of religiosity on adolescent sexual behavior. Journal of Adolescent Research, 19, 677-697. doi: $10.1177 / 0743558403260019$

Sheu, M.-1., Hu, T.-w., Keeler, T.E., Ong, M., \& Sung, H.-Y. (2004). The effect of a major cigarette price change on smoking behavior in California: A zero-inflated negative binomial model. Health Economics, 13(8), 781-791. doi: 10.1002/hec.849

Skog, O.-J. (1985). The collectivity of drinking cultures: A theory of the distribution of alcohol consumption. British Journal of Addiction, 80(1), 83-99. doi: 10.1111/j.13600443.1985.tb05294.x

Vereecken, C.A., Maes, L., \& De Bacquer, D. (2004). The influence of parental occupation and the pupils' educational level on lifestyle behaviors among adolescents in Belgium. Journal of Adolescent Health, 34(4), 330-338. doi: 10.1016/j.jadohealth.2003.07.011

Viscusi, W.K. (1990). Do smokers underestimate risks? Journal of Political Economy, 98, 12531269. Retrieved from: http://www.jstor.org/stable/2937757 
Wilks, J. (1986). The relative importance of parents and friends in adolescent decision making. Journal of Youth and Adolescence, 15(4), 323-334. doi: 10.1007/BF02145729

Wooldridge, J.M. (2002). Econometric analysis of cross section and panel data. Cambridge, Mass: MIT Press.

You, W., \& Davis, G. C. (2011). Childhood overweight: Does quality of parental childcare time matter? Journal of Family and Economic Issues, 32(2), 219-232. doi:10.1007/s10834011-9245-4 
Table 1: Summary Statistics for Risky Health Behaviors

\begin{tabular}{|c|c|c|c|c|}
\hline & \multicolumn{2}{|c|}{ Preachers' Kids } & \multicolumn{2}{|c|}{ Non-PKs } \\
\hline & Mean & St. Dev. & Mean & St. Dev. \\
\hline Any Alcohol in the Past Month, 1982 & 0.552 & 0.506 & 0.651 & 0.477 \\
\hline Any Alcohol in the Past Month, 1983 & 0.517 & 0.509 & 0.661 & 0.473 \\
\hline Any Alcohol in the Past Month, 1984 & 0.517 & 0.509 & 0.689 & 0.463 \\
\hline Any Alcohol in the Past Month, 1985 & 0.455 & 0.510 & 0.663 & 0.473 \\
\hline Any Alcohol in the Past Month, 1988 & 0.450 & 0.510 & 0.669 & 0.471 \\
\hline Any Alcohol in the Past Month, 1989 & 0.524 & 0.512 & 0.628 & 0.483 \\
\hline Any Alcohol in the Past Month, 1992 & 0.579 & 0.507 & 0.638 & 0.481 \\
\hline Any Alcohol in the Past Month, 1994 & 0.588 & 0.507 & 0.598 & 0.490 \\
\hline Any Alcohol in the Past Month, 2002 & 0.429 & 0.514 & 0.538 & 0.499 \\
\hline Any Alcohol in the Past Month, 2006 & 0.462 & 0.519 & 0.519 & 0.500 \\
\hline Any Alcohol in the Past Month, 2008 & 0.571 & 0.514 & 0.549 & 0.498 \\
\hline Number of Days Drank in the Past Month, 1983 & 3.621 & 6.366 & 4.757 & 6.585 \\
\hline Number of Days Drank in the Past Month, 1984 & 4.379 & 7.447 & 5.167 & 6.896 \\
\hline Number of Days Drank in the Past Month, 1985 & 3.909 & 6.346 & 4.887 & 6.828 \\
\hline Number of Days Drank in the Past Month, 1988 & 5.150 & 7.095 & 5.004 & 6.963 \\
\hline Number of Days Drank in the Past Month, 1989 & 5.667 & 7.908 & 4.544 & 6.735 \\
\hline Number of Days Drank in the Past Month, 1994 & 6.647 & 10.553 & 4.562 & 7.008 \\
\hline Number of Days Drank in the Past Month, 2002 & 4.857 & 7.695 & 4.182 & 7.004 \\
\hline Number of Days Drank in the Past Month, 2006 & 3.385 & 4.942 & 4.026 & 6.988 \\
\hline Number of Days Drank in the Past Month, 2008 & 7.071 & 9.571 & 4.584 & 7.544 \\
\hline Number of Days with 5+ Drinks Past Month, 1983 & 0.690 & 2.089 & 1.343 & 3.313 \\
\hline Number of Days with 5+ Drinks Past Month, 1984 & 1.310 & 5.581 & 1.455 & 3.517 \\
\hline Number of Days with 5+ Drinks Past Month, 1985 & 0.500 & 1.946 & 1.235 & 3.484 \\
\hline Smoked 100 or more Cigarettes in Lifetime, 1992 & 0.579 & 0.507 & 0.489 & 0.500 \\
\hline Smoked 100 or more Cigarettes in Lifetime, 1994 & 0.529 & 0.514 & 0.497 & 0.500 \\
\hline Smoked 100 or more Cigarettes in Lifetime, 1998 & 0.533 & 0.516 & 0.495 & 0.500 \\
\hline Smoked Any Cigarettes in the Past Month, 1984 & 0.241 & 0.435 & 0.430 & 0.495 \\
\hline Smoked Any Cigarettes in the Past Month, 1992 & 0.316 & 0.478 & 0.341 & 0.474 \\
\hline Smoked Any Cigarettes in the Past Month, 1994 & 0.353 & 0.493 & 0.328 & 0.470 \\
\hline Smoked Any Cigarettes in the Past Month, 1998 & 0.333 & 0.488 & 0.308 & 0.462 \\
\hline Smoked Any Cigarettes in the Past Month, 2008 & 0.357 & 0.497 & 0.274 & 0.446 \\
\hline Number of Cigarettes per Day the Past Month, 1984 & 2.448 & 6.308 & 6.701 & 11.044 \\
\hline Number of Cigarettes per Day the Past Month, 1992 & 4.333 & 7.956 & 5.221 & 9.745 \\
\hline Number of Cigarettes per Day the Past Month, 1994 & 5.938 & 11.138 & 5.083 & 9.582 \\
\hline Number of Cigarettes per Day the Past Month, 1998 & 4.643 & 7.958 & 4.647 & 9.185 \\
\hline Number of Cigarettes per Day the Past Month, 2008 & 2.250 & 4.137 & 3.369 & 7.624 \\
\hline Any Marijuana in Past Year, 1980 & 0.345 & 0.484 & 0.469 & 0.499 \\
\hline Any Other Drugs in Past Year, 1980 & 0.069 & 0.258 & 0.195 & 0.396 \\
\hline
\end{tabular}


Table 2. Effect of Being a Preacher's Kid on Alcohol Consumption
A. Baseline Controls

\begin{tabular}{|c|c|c|c|c|c|c|}
\hline \multirow[t]{2}{*}{ Year } & \multirow[t]{2}{*}{ Age } & \multirow[t]{2}{*}{$\begin{array}{l}\text { Any Alcohol } \\
\text { Consumption in the } \\
\text { Past Month }\end{array}$} & \multicolumn{2}{|c|}{$\begin{array}{l}\text { Number of Days Drank in the } \\
\text { Past Month }\end{array}$} & \multicolumn{2}{|c|}{$\begin{array}{l}\text { Number of Days with Five or } \\
\text { More Drinks in the Past Month }\end{array}$} \\
\hline & & & Certain Zero & Count & Certain Zero & Count \\
\hline 1982 & $17-25$ & $\begin{array}{l}0.344 * * \\
(0.006)\end{array}$ & & & & \\
\hline 1983 & $18-26$ & $\begin{array}{l}0.279 * * \\
(0.001)\end{array}$ & $\begin{array}{c}6.180 * * * \\
(0.000)\end{array}$ & $\begin{array}{c}0.856 \\
(0.577)\end{array}$ & $\begin{array}{c}12.187 * * * \\
(0.000)\end{array}$ & $\begin{array}{c}2.100 \\
(0.340)\end{array}$ \\
\hline 1984 & $19-27$ & $\begin{array}{c}0.255^{* * *} \\
(0.000)\end{array}$ & $\begin{array}{c}7.443 * * * \\
(0.000)\end{array}$ & $\begin{array}{c}1.145 \\
(0.616)\end{array}$ & $\begin{array}{l}7.072 * * \\
(0.001)\end{array}$ & $\begin{array}{c}2.423 \\
(0.148)\end{array}$ \\
\hline 1985 & $20-28$ & $\begin{array}{l}0.219 * * \\
(0.001)\end{array}$ & $\begin{array}{c}9.237 * * * \\
(0.000)\end{array}$ & $\begin{array}{c}1.153 \\
(0.675)\end{array}$ & $\begin{array}{l}4.751^{*} \\
(0.086)\end{array}$ & $\begin{array}{c}1.085 \\
(0.930)\end{array}$ \\
\hline 1988 & $23-31$ & $\begin{array}{l}0.238 * * \\
(0.002)\end{array}$ & $\begin{array}{l}7.796 * * * \\
(0.000)\end{array}$ & $\begin{array}{c}1.477 \\
(0.268)\end{array}$ & & \\
\hline 1989 & $24-32$ & $\begin{array}{l}0.379 * \\
(0.032)\end{array}$ & $\begin{array}{l}4.538 * * \\
(0.006)\end{array}$ & $\begin{array}{c}1.394 \\
(0.311)\end{array}$ & & \\
\hline 1992 & $27-35$ & $\begin{array}{c}0.523 \\
(0.173)\end{array}$ & & & & \\
\hline 1994 & $29-37$ & $\begin{array}{c}0.556 \\
(0.247)\end{array}$ & $\begin{array}{c}2.732 \\
(0.111)\end{array}$ & $\begin{array}{c}1.302 \\
(0.452)\end{array}$ & & \\
\hline 2002 & $37-45$ & $\begin{array}{l}0.392 \dagger \\
(0.090)\end{array}$ & $\begin{array}{l}3.891^{*} \\
(0.035)\end{array}$ & $\begin{array}{c}1.309 \\
(0.574)\end{array}$ & & \\
\hline 2006 & $41-49$ & $\begin{array}{c}0.473 \\
(0.190)\end{array}$ & $\begin{array}{c}2.729 \\
(0.212)\end{array}$ & $\begin{array}{c}0.781 \\
(0.626)\end{array}$ & & \\
\hline 2008 & $43-51$ & $\begin{array}{c}0.677 \\
(0.480)\end{array}$ & $\begin{array}{c}1.653 \\
(0.558)\end{array}$ & $\begin{array}{c}1.106 \\
(0.816)\end{array}$ & & \\
\hline
\end{tabular}




\section{B. Including Controls for Religious Attendance and Affiliation}

\begin{tabular}{|c|c|c|c|c|c|c|}
\hline \multirow[t]{2}{*}{ Year } & \multirow[t]{2}{*}{ Age } & \multirow[t]{2}{*}{$\begin{array}{l}\text { Any Alcohol } \\
\text { Consumption in the } \\
\text { Past Month }\end{array}$} & \multicolumn{2}{|c|}{$\begin{array}{l}\text { Number of Days Drank in the } \\
\text { Past Month }\end{array}$} & \multicolumn{2}{|c|}{$\begin{array}{c}\text { Number of Days with Five or } \\
\text { More Drinks in the Past } \\
\text { Month }\end{array}$} \\
\hline & & & Certain Zero & Count & Certain Zero & Count \\
\hline 1982 & $17-25$ & $\begin{array}{l}0.524 \dagger \\
(0.099)\end{array}$ & & & & \\
\hline 1983 & $18-26$ & $\begin{array}{l}0.433 * \\
(0.032)\end{array}$ & $\begin{array}{l}3.603 * * \\
(0.008)\end{array}$ & $\begin{array}{c}0.993 \\
(0.980)\end{array}$ & $\begin{array}{l}7.107^{* *} \\
(0.005)\end{array}$ & $\begin{array}{c}2.537 \\
(0.223)\end{array}$ \\
\hline 1984 & $19-27$ & $\begin{array}{l}0.368^{* *} \\
(0.010)\end{array}$ & $\begin{array}{l}4.314 * * \\
(0.002)\end{array}$ & $\begin{array}{c}1.274 \\
(0.362)\end{array}$ & $\begin{array}{l}4.507 * \\
(0.011)\end{array}$ & $\begin{array}{l}3.271 \dagger \\
(0.052)\end{array}$ \\
\hline 1985 & $20-28$ & $\begin{array}{l}0.309 * * \\
(0.008)\end{array}$ & $\begin{array}{c}6.080 * * * \\
(0.000)\end{array}$ & $\begin{array}{c}1.390 \\
(0.328)\end{array}$ & $\begin{array}{c}2.586 \\
(0.289)\end{array}$ & $\begin{array}{c}1.023 \\
(0.980)\end{array}$ \\
\hline 1988 & $23-31$ & $\begin{array}{l}0.360^{*} \\
(0.029)\end{array}$ & $\begin{array}{l}4.273 * * \\
(0.005)\end{array}$ & $\begin{array}{c}1.667 \\
(0.144)\end{array}$ & & \\
\hline 1989 & $24-32$ & $\begin{array}{c}0.528 \\
(0.165)\end{array}$ & $\begin{array}{c}2.444 \\
(0.102)\end{array}$ & $\begin{array}{c}1.519 \\
(0.182)\end{array}$ & & \\
\hline 1992 & $27-35$ & $\begin{array}{c}0.675 \\
(0.413)\end{array}$ & & & & \\
\hline 1994 & $29-37$ & $\begin{array}{c}0.741 \\
(0.557)\end{array}$ & $\begin{array}{c}1.928 \\
(0.298)\end{array}$ & $\begin{array}{c}1.523 \\
(0.229)\end{array}$ & & \\
\hline 2002 & $37-45$ & $\begin{array}{c}0.537 \\
(0.264)\end{array}$ & $\begin{array}{c}2.661 \\
(0.133)\end{array}$ & $\begin{array}{c}1.594 \\
(0.330)\end{array}$ & & \\
\hline 2006 & $41-49$ & $\begin{array}{c}0.623 \\
(0.409)\end{array}$ & $\begin{array}{c}2.053 \\
(0.348)\end{array}$ & $\begin{array}{c}0.916 \\
(0.864)\end{array}$ & & \\
\hline 2008 & $43-51$ & $\begin{array}{c}0.878 \\
(0.814)\end{array}$ & $\begin{array}{c}1.010 \\
(0.992)\end{array}$ & $\begin{array}{c}1.155 \\
(0.736) \\
\end{array}$ & & \\
\hline
\end{tabular}

Notes: Models are estimated via logit and zero-inflated negative binomial regression with a logit inflation function. Odds-ratios are reported for logit results. For count results, the number reported is $\exp \left(\beta_{i}\right)$, which provides the multiplicative factor for a one-unit increase in the independent variable. In both cases, the relevant test is against the null of the reported value being equal to 1 . Baseline controls include dummy variables for single year of age, whether an individual is female, Black, Hispanic, lived in an SMSA in 1979, region of residence in 1979, father's education, mother's education, whether the mother worked, whether respondent lived with biological father or other father figure at age 14, the presence and number of siblings, the presence and number of older siblings, and the Duncan Socioeconomic Index (SEI) of occupational prestige for the father's occupation. $p$-values in parentheses.

$\dagger \mathrm{p}<0.10 ; * \mathrm{p}<0.05 ; * * \mathrm{p}<0.01 ; * * * \mathrm{p}<0.001$. 
Table 3: Effects of Being a Preacher's Kid on Cigarette Smoking

\begin{tabular}{|c|c|c|c|c|c|}
\hline \multirow[t]{2}{*}{ Year } & \multirow[t]{2}{*}{ Age } & \multirow[t]{2}{*}{$\begin{array}{l}\text { Smoked } 100 \text { or } \\
\text { more Cigarettes } \\
\text { in Lifetime }\end{array}$} & \multirow[t]{2}{*}{$\begin{array}{c}\text { Smoked Any } \\
\text { Cigarettes in the } \\
\text { Past Month }\end{array}$} & \multicolumn{2}{|c|}{$\begin{array}{l}\text { Number of Cigarettes per } \\
\text { Day in the Past Month }\end{array}$} \\
\hline & & & & $\begin{array}{l}\text { Certain } \\
\text { Zero }\end{array}$ & Count \\
\hline \multicolumn{6}{|c|}{ A. Baseline Controls } \\
\hline \multirow[t]{2}{*}{1984} & $19-27$ & & 0.487 & & \\
\hline & & & $(0.104)$ & & \\
\hline \multirow[t]{2}{*}{1992} & $27-35$ & 1.617 & 1.100 & 0.866 & 1.057 \\
\hline & & $(0.310)$ & $(0.850)$ & $(0.790)$ & $(0.824)$ \\
\hline \multirow[t]{2}{*}{1994} & $29-37$ & 1.248 & 1.336 & 0.727 & 1.314 \\
\hline & & $(0.656)$ & $(0.578)$ & $(0.565)$ & $(0.239)$ \\
\hline \multirow[t]{2}{*}{1998} & $33-41$ & 1.261 & 1.430 & 0.766 & 1.121 \\
\hline & & $(0.662)$ & $(0.523)$ & $(0.660)$ & $(0.698)$ \\
\hline \multirow[t]{2}{*}{2008} & $43-51$ & & 1.966 & & \\
\hline & & & $(0.238)$ & & \\
\hline
\end{tabular}

$\begin{array}{cccccc}\text { B. Including Controls for Religious Attendance and Affiliation } \\ 1984 & 19-27 & & 0.617 & & \\ & & & & \\ 1 \\ 1992 & 27-35 & 2.059 & 1.370 & 0.668 & 1.027 \\ & & (0.129) & (0.534) & (0.456) & (0.914) \\ 1994 & 29-37 & 1.574 & 1.715 & 0.560 & 1.256 \\ & & (0.365) & (0.303) & (0.298) & (0.324) \\ 1998 & 33-41 & 1.590 & 1.876 & 0.568 & 1.103 \\ & & (0.385) & (0.265) & (0.355) & (0.738) \\ 2008 & 43-51 & & 2.442 & & \\ & & & (0.120) & & \\ \end{array}$

Notes: Models are estimated via logit and zero-inflated negative binomial regression with a logit inflation function. Odds-ratios are reported for logit results, while multiplicative factors for a oneunit increase in the regressor $\left(\exp \left(\beta_{i}\right)\right)$ are reported for the count model. In both cases, the relevant test is against the null of the reported value being equal to 1 . Baseline controls include dummy variables for single year of age, whether an individual is female, Black, Hispanic, lived in an SMSA in 1979, region of residence in 1979, father's education, mother's education, whether the mother worked, whether respondent lived with biological father or other father figure at age 14, the presence and number of siblings, the presence and number of older siblings, and the Duncan Socioeconomic Index (SEI) of occupational prestige for the father's occupation. $p$-values in parentheses. 
Table 4: Effects of Being a PK on Marijuana and Other Drug Use

\begin{tabular}{|c|c|c|c|}
\hline Year & Age & $\begin{array}{l}\text { Any Marijuana } \\
\text { in Past Year }\end{array}$ & $\begin{array}{c}\text { Any Other Drugs in } \\
\text { Past Year }\end{array}$ \\
\hline \multicolumn{2}{|c|}{ A. Baseline Controls } & $0.468 \dagger$ & $0.226^{*}$ \\
\hline 1980 & $14-22$ & $(0.058)$ & $(0.045)$ \\
\hline \multicolumn{4}{|c|}{ B. Including Controls for Religious Attendance and Affiliation } \\
\hline 1980 & $14-22$ & $\begin{array}{c}0.675 \\
(0.330)\end{array}$ & $\begin{array}{c}0.331 \\
(0.138)\end{array}$ \\
\hline
\end{tabular}

Notes: Models are estimated via logit. Odds ratios are reported.

$p$-values in parentheses. $\dagger \mathrm{p}<0.10 ; * \mathrm{p}<0.05 ; * * \mathrm{p}<0.01 ; * * * \mathrm{p}<0.001$. 
Figure 1. Certain-zero odds-ratios and Incidence Ratio for number of drinks, conditional on not being a certain zero, over time
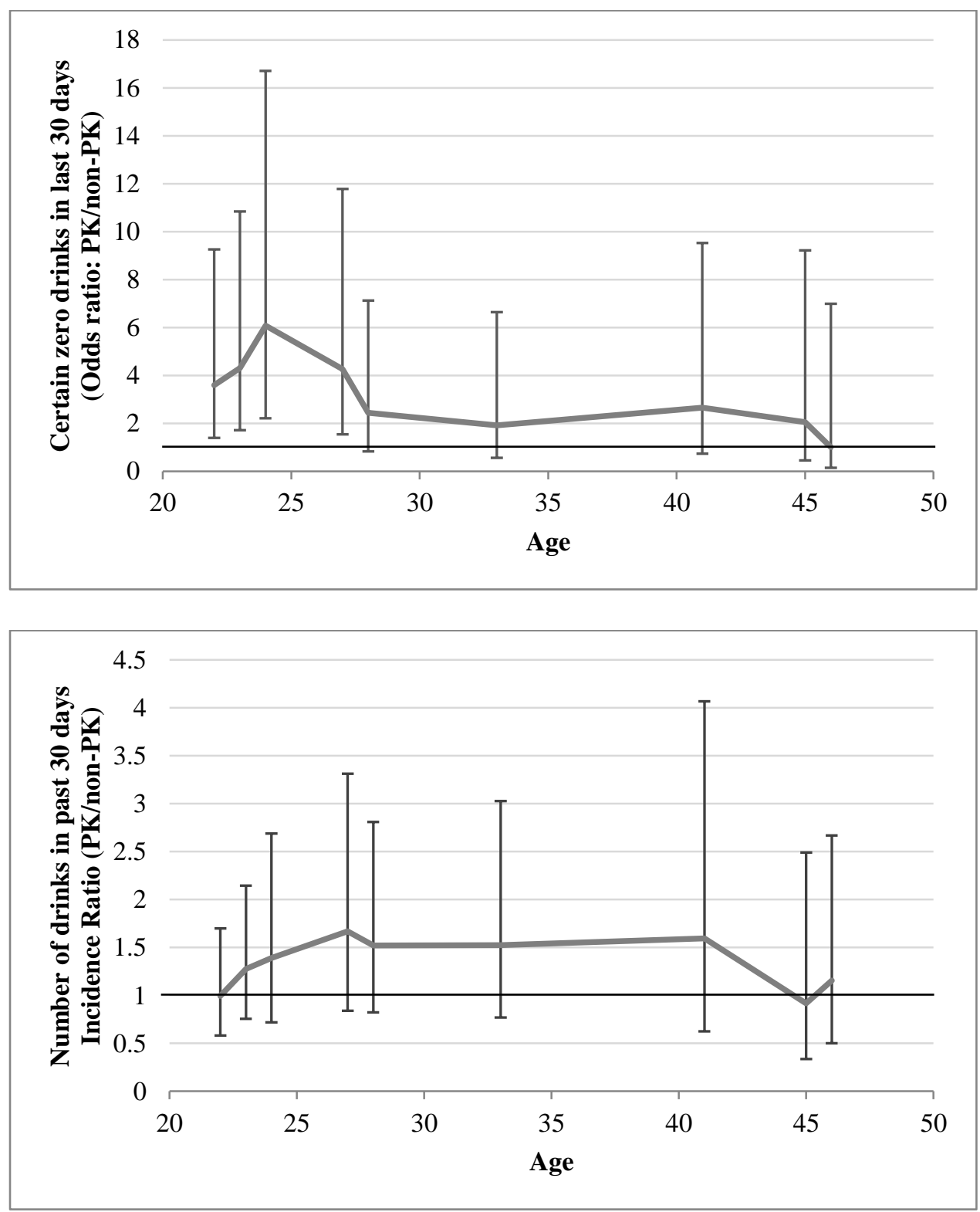

Notes: Controls include dummy variables for single year of age, whether an individual is female, Black, Hispanic, lived in an SMSA in 1979, region of residence in 1979, father's education, mother's education, whether the mother worked, whether respondent lived with biological father or other father figure at age 14, the presence and number of siblings, the presence and number of older siblings, the Duncan Socioeconomic Index (SEI) of occupational prestige for the father's occupation, and controls for religious attendance and affiliation. 